DOI: 10.12731/2077-1770-2019-4-292-303

УДК 811.111-26

\title{
ВОЗРАСТНЫЕ СЕМАНТИКО-СТИЛИСТИЧЕСКИЕ ФУНКЦИИ МЕСТОИМЕНИЯ Я-ОNЕ В РЕЧИ АНГЛИЧАН ПРЕСТИЖНЫХ СОЦИАЛЬНЫХ ГРУПП
}

Тисленкова И.А., Глебова Е.А., Бганцева И.В.

Статья посвящена анализу ранее не изученных возрастных особенностей функиионирования местоимения подлежащуего я-опе 8 речи англичан-представителей социальной элить Великобритании.

Цель исследования состоит в сочииолигвистическом анализе nьесы Тома Cтопnарда «The Invention of Love» для выявления возрастных групп престижных слоёв населения, употребляющих местоимение опе в значении «я», и описания его функиий.

Основные методы, использованные в исследовании: соичиолингвистический анализ речи персонажа посредством социолингвистических категорий.

Результаты. Проведённый анализ контекстов употребления подлежащзего я-опе позволил прийти к выводу о том, что в молодости данное местоимение выступает средством соииокультурной самоидентификации личности, в зрелости - способом самовыражения, в старости - самооценки и транслящии опыта.

Область применения результатов. Полученные в процессе исследования данные могут быть использованы на занятиях по курсу перевода, стилистики и семиотики.

Ключевые слова: местоимение я-опе; язык аристократии; высиие классы; семантико-стилистические функиии; возрастные характеристики речи.

\section{AGE-RELATED SEMANTIC AND STYLISTIC FUNCTIONS OF PRONOUN I-ONE IN THE SPEECH OF UPPER-CLASS ENGLISHMEN}

\section{Tislenkova I.A., Glebova E.A., Bgantseva I.V.}

The article is devoted to the analysis of previously unstudied age-related specific in functioning of the subject pronoun I-one in the speech of British social elite. 
The aim of the study is to conduct sociolinguistic analysis of Tom Stoppard's play "The Invention of Love" to identify age groups of prestigious social layers that use pronoun one in the meaning of "I", and describe its functions.

The main methods used in the study include sociolinguistic analysis of character's speech by means of sociolinguistic categories.

Results. Analysis of the contexts, where pronoun I-one is used, allowed us to come to conclusion that in youth this pronoun functions as a means of social and cultural self-identification, in maturity as a way of self-expression and in old age as method of self-esteem and teaching experience.

Practical implications. The data, obtained in the process of research, can be used in teaching translation, stylistics and semiotics.

Keywords: pronoun I-one; language of aristocracy; upper classes; semantic and stylistic functions; age characteristics of speech.

Проблемы языка и идентификации изучаются многими современными исследователеми $[8,15,7,10,9]$. По мнению Гураль С.К., язык напрямую связан с тем, как говорящий позиционирует себя и видит свою роль в британском обществе [3, с. 113]. Большая часть самоидентификации обусловлена именно языковыми средствами, с помощью которых коммуникант общается с другими людьми и миром $[14$, с. 62$]$. Одним из таких средств является употребление неопределенного местоимения one в значении первого лица единственного числа.

Современные исследования показывают, что я-опе употребляется исключительно представителями привилегированного класса британского общества, являясь социальной разновидностью языка элиты. Однако неизученным остается вопрос о возрастном статусе аристократов, использующих указанное местоимение в данном значении, что определяет новизну и актуальность исследования.

Цель исследования состоит в том, чтобы установить, какие возрастные группы престижных слоёв населения преимущественно включают в свои высказывания местоимение опe в значении «я». 
В настоящей работе возрастные особенности использования местоимения я-опе рассматриваются с точки зрения социолингвистики, а также в рамках метода социолингвистического анализа речи персонажа на основе социолингвистических категорий, предложенного профессором Ивушкиной Т.А. в монографии «Язык английской аристократии: социально-исторический аспект» [7].

Также, исследование основывается на следующих теоретических положениях:

1. Понятии социальной индикации высказываний говорящего, разработанном В. Карасиком и изложенном в работе «Язык социального статуса» [9];

2. Тематическом содержании высказывания М. Чижевской в книге «Язык, речь и речевая характеристика (Вопросы изучения речи персонажа)» [17];

3. Выводах В. Шаховского [18], идеях В. Пищальниковой [12] и Р. Грановской [2] о соотношении эмоций, эмоциональности речи и возраста говорящего;

4. Выводах А. Ермолаева о возможности определения возраста говорящего путем использования стереотипных, клишированных фраз и речевых паттернов [6].

\section{Результаты исследования}

В зависимости от типа деятельности человека, который является ведущим для каждой из них, мы выделяем:

1. Молодое поколение (20-35 лет);

2. Среднее поколение (35-50 лет);

3. Старшее поколение (после 50 лет) [15, с. 132].

Для реализации поставленной цели обратимся к анализу суждений англичан трёх возрастных групп высшего света. Для проведения исследования мы выбрали речь героев произведения «Изобретение любви» 1997 г. популярного в настоящее время английского драматурга Тома Стоппарда. Персонажная речь привлекается нами к исследованию не случайно, в связи с тем, что язык современной драматургии максимально приближен к разговорному языку [1]. 
Используя указанные теоретические выводы, рассмотрим реплики действующих лиц пьесы, содержащие местоимение я-опe:

- молодое поколение - Альфред Хаусмен 20 лет, студент-антиковед Оксфордского университета;

- среднее поколение - Уолтер Пейтер 38 лет, профессор, эссеист и искусствовед;

- старшее поколение - Альфред Хаусмен 77 лет, знаменитый поэт.

В результате сплошной выборки текста местоимение я-опе было обнаружено в высказываниях всех возрастных групп: молодого, среднего и старшего поколений. Рассмотрим некоторые примеры более подробно.

\section{Сентенции молодого англичанина:}

\section{Housman}

"Baehrens should make everyone obsolete - isn't that why one edits Propertius? < ...>-but one has hardly settled down with Baehrens before one is jolted out of one's chair by something like cunctas in one-onefive" [21, p. 3].

\section{Хаусмен}

«Беренс способен затмить всех, кто писал до него, - а разве не для этого я сейчас работаю над комментарием к новому изданию элегий Пропериия? <...> однако едва я смог поравняться с ним, как от его cunctas вместо castas в Книге первой, элегии 1, стихе 5 я чуть не потерял рассудок» [перевод наш].

Юноша явно бравирует своими исключительными знаниями, высокой образованностью, когда показывает, как хорошо он разбирается в оттенках значения латинских слов cunctas «вся» и castas «чистая» в строках древнеримского элегического поэта: «Любовь научила меня ненавидеть чистых девиц». Альфред наслаждается собственной значимостью, заявляя, что если делать перевод этого лирического фрагмента, руководствуясь предложением Беренса, то смысл строк приобретает совсем не то значение, которое первоначально вкладывал в него Проперций: «Любовь научила меня ненавидеть всех девиц» [16, с. 22]. 
Многократное употребление местоимения я-оne в соседних предложениях помогает молодому аристократу придать вес своему «открытию», выглядеть в глазах сокурсников-слушателей солидно, повысить свою самооценку, ведь он, будучи только студентом, бросает вызов признанному авторитету - немецкому филологу-классику Паулю Беренсу титулованному переводчику таких римских классиков, как Минуций, Тацит, Проперций, Стаций, Катулл, Тибулл, Гораций, Феликс. Костецкая А. отмечает, что студенты из социальной элиты часто подражают известным и популярным людям, перенимая их мысли и манеры [9, с. 80]. Наш пример показывает, что используя я-опe, Хаумен имитирует Беренса с целью придать своей речи высокостатусные характеристики. Такая практика позволяет молодёжи из высшего общества выйти за рамки своей индивидуальности, реализовать потребность в самовыражении, высказать своё мнение [11].

Сентенции англичанина средней возрастной группы:

\section{Pater}

"As for arts-and-crafts, it is very well for the people; without it, Liberty's would be at risk, in fact it would be closed, but the true Aesthetic spirit goes back to Florence, Venice, Rome-Japanese apart. One sees it plain in Michelangelo's David-legs apart” [21, p. 17].

\section{Пейтер}

«Если говорить о кустарных промьслах, то они хороши как средство эстетического самовыражения для простолюдинов; без них художественному салону Liberty's грозил бы крах вплоть до закрытия. Истинная же красота эстетизма присущуа лишь Флоренщии, Венеции, Риму - не считая Японии. Я отчётливо её вижу в образе Давида Микеланджело - того, что стоит, отставив ногу» [перевод наш].

Исследователи подчеркивают, что в период зрелости человек достигает вершины профессиональной карьеры [5, с. 65]. Он обладает всеми умениями и навыками, составляющими основу жизненного опыта, открыто заявляет о своих ценностях, установках и принципах [4, с. 409]. Из приведённого высказывания видно, что имея обширные познания и собственную точку зрения в искусстве, художественный 
критик Пейтер избегает тривиальных способов излагать свою позицию. Он прибегает к использованию местоимения я-опе, которое показывает такие черты речи, как тяготение к обобщенности, рассуждению об универсальных понятиях с оттенком платонизма.

Как отмечает Крюков Д., местоимение-подлежащее опе обеспечивает выход рассуждения говорящего на более абстрактный уровень. Также, я-опе обладает социальным значением, так как предполагает наличие единой позиции определенной группы людей, от имени которой высказывается автор [10, с. 192].

Использование я-опе в этом отрывке речи связано со стремлением рассмотреть проблему под новым углом зрения, оценить ее непредвзято: оценивая скульптуру Микеланжело, Пейтер выражает восхищение мужской красотой, утверждая, что эротический подтекст предполагается самой природой искусства. Употребление безличного местоимения первого лица единственного числа one предполагает выход за рамки непосредственного личного опыта [19].

\section{Сентенции англичанина старшей возрастной группы:}

\section{AEH}

"No fear of that. The jackals are another matter. One used to say, 'After I'm dead'. The consolation is not as complete as one had supposed. There - the painter is belayed" [21, p. 1].

\section{AЭX}

«Это не страшно. Шакаль - другое дело. Когда-то я говорил, что мне безразлично, что будет со мной после смерти. Утешение в смерти не столь полное, как я предполагал. Ну, вот и всё: художнику - конеиџ [перевод наш].

По мнению Стернина И., речь представителей старшего поколения практически не изучена в возрастной и коммуникативной лингвистике [13, с. 5]. Местоимение я-опе показывает сфокусированность Хаусмена на своих переживаниях в связи с окончанием жизни и подготовкой к переходу его души в иное состояние. В речи этого персонажа неопределенное местоимение первого лица единственного числа one присутствует в высказываниях, касающихся личной сферы, в которых герой дает оценку своим жизненным достижени- 
ям и событиям биографии, стремится извлечь уроки из допущенных ошибок, найти пути адаптации к новому социальному положению.

\section{Выводы}

Еще в конце XX столетия многие англичане придерживались «правильного английского» [3, с. 114]. К настоящему времени King's English перешел в статус социолекта, став языком меньшинства - верхушки общества [20, с. 365].

В результате проведённого исследования было установлено, что грамматический индикатор элитарного английского - местоимение-подлежащее $я$-опе используется аристократами всех трёх поколений.

Значение местоимения подлежащего оne обладает широким спектром функций, которые выводятся из контекста беседы:

- молодёжь использует такое подлежащее для выражения собственной позиции, озвучивания установок и предпочтений, реализации своей концепции жизни; употребление я-опе является средством достижения социального, профессионального и мировоззренческого самоопределения, способом включения личности в социальную структуру, сохранения речевых традиций прошлого;

- с помощью подлежащего я-опе знатные люди зрелого возраста стремятся получить от окружающих признание своих заслуг, положительную оценку накопленного ими опыта, достижений; данное местоимение помогает демонстрировать глубокие научные познания, приверженность нравственным принципам, делать разного рода обобщения;

- в речи геронтов рассматриваемое местоимение используется для философских обобщений своего результатов прожитой жизни с целью назидания и передачи опыта.

\section{Список литературы}

1. Борисенко Н.Д. Моделирование гендерного аспекта персонажной речи в английской драме второй половины XX столетия // Культура народов Причерноморья, 2002. №32. С. 326-329. 
2. Грановская Р.М. Элементы практической психологии. СПб.: Речь, 2003.

3. Гураль С.К. Как правильно говорить по-английски или есть ли «стандартный английский»? // Вестник Томского государственного университета. Томск 2006. С. 113-115.

4. Ермаков С.А. Проблема выбора жизненного пути человека в философии // Вестник Нижегородского университета им. Н.И. Лобачевского. Серия: Социальные науки, 2004. № 1. С. 408-415.

5. Ермаков С.А., Мезина Л.Г. Путь жизни человека как проблема философской антропологии // Известия высших учебных заведений. Поволжский регион. Гуманитарные науки, 2012. № 3. С. 60-68.

6. Ермолаев А.К. Моделирование личности по тексту: обобщение опыта оперативно-розыскной работы. Дис....канд. филол. наук: 10.02.19. Барнаул, 1999.

7. Ивушкина Т.А. Социолингвистические аспекты развития английской речи (на материале речевых характеристик представителей высших классов Великобритании в произведениях английской художественной литературы): Афтореф. дисс. ... д-ра филол. наук. М., 1998.

8. Карасик В.И. Язык социального статуса. М.: ИТДГК «Гнозис», 2002.

9. Костецкая А.Г. Социолингвистические характеристики речи образованной молодежи Великобритании и США: автореф. дис....канд. филол. наук. Волгоград, 2001.

10.Крюков Д.В. Социолингвистические характеристики писем английской аристократии Викторианской эпохи: дисс... на соиск. уч. степени канд. филол. наук. Волгоград, 2001.

11. Магидова И.М. Теория и практика прагмалингвистического регистра английской речи: дисс. на соиск. уч. степени д-ра филол. наук. Москва, 1989.

12. Пищальникова В.А. Проблема смысла художественного текста. Психо-лингвистический аспект. Новосибирск, 1992.

13. Стернин И.А. Общение со старшим поколением. Изд.4, испр. Воронеж: «Истоки», 2013. 
14. Тисленкова И.А. Исторические реалии - маркеры речи пожилого человека // Актуальные вопросы науки: Материалы XXXVI Международной научно-практической конференции (09.02.2018). М.: «Спутник+, 2018. С. 62-64.

15. Тисленкова И.А. Культурно-исторические реалии прошедшей эпохи в речи персонажей современной британской драмы. Волгоград: «Известия ВГСПУ» №2 (125), 2018. С. 132-136.

16. Том Стоппард. Изобретение любви. Азбука-классика, 2009.

17. Чижевская М.И. Язык, речь и речевая характеристика: (Вопр. изуч. речи персонажа) / М.И. Чижевская; МГУ им. М.В. Ломоносова. М.: Изд-во МГУ. 1986.

18. Шаховский В.И. Лингвистическая теория эмоций. Монография. М.: Гнозис, 2008.

19. Berstein B. Language and social context. London: Penguin Books, 1972.

20. Crystal D. The Cambridge Encyclopedia of the English Language. Cambridge, 2001.

21. Stoppard T. The Invention of Love. Grove Press. New York, 1997.

\section{References}

1. Borisenko N.D. Modelirovanie gendernogo aspekta personazhnoj rechi v anglijskoj drame vtoroj poloviny XX stoletija [Modeling gender aspect of character speech in English drama of the second half of the XX century]. Kul'tura narodov Prichernomor 'ja, 2002. №32, pp. 326-329.

2. Granovskaja R.M. Jelementy prakticheskoj psihologii [Elements of practical psychology]. SPb.: Rech', 2003.

3. Gural' S.K. Kak pravil'no govorit' po-anglijski ili est' li «standartnyj anglijskij»? [ How to speak English correctly or is there "standard English"?]. Vestnik Tomskogo gosudarstvennogo universiteta. Tomsk 2006, pp. 113-115.

4. Ermakov S.A. Problema vybora zhiznennogo puti cheloveka v filosofii [The problem of choosing a person's life path in philosophy]. Vestnik Nizhegorodskogo universiteta im. N.I. Lobachevskogo. Serija: Social'nye nauki, 2004. № 1, pp. 408-415. 
5. Ermakov S.A., Mezina L.G. Put' zhizni cheloveka kak problema filosofskoj antropologii [The way of human life as a problem of philosophical anthropology]. Izvestija vysshih uchebnyh zavedenij. Povolzhskij region. Gumanitarnye nauki, 2012. № 3, pp. 60-68.

6. Ermolaev A.K. Modelirovanie lichnosti po tekstu: obobshhenie opyta operativno-rozysknoj raboty [Personality modelling based on the text: generalization of experience of officer work]: Dis....kand. filol. nauk: 10.02.19. Barnaul, 1999.

7. Ivushkina T.A. Sociolingvisticheskie aspekty razvitija anglijskoj rechi (na materiale rechevyh harakteristik predstavitelej vysshih klassov Velikobritanii v proizvedenijah anglijskoj hudozhestvennoj literatury) [Sociolinguistic aspects of English speech development (based on British upper-class characters speech characteristics from English fiction)]: Aftoref. diss. ...d-ra filol. nauk. M., 1998.

8. Karasik V.I. Jazyk social'nogo statusa [Language of social status] M.: ITDGK «Gnozis», 2002.

9. Kosteckaja A.G. Sociolingvisticheskie harakteristiki rechi obrazovannoj molodezhi Velikobritanii i SShA [Sociolinguistic characteristics of educated youth speech in Great Britain and the USA]: avtoref. dis....kand. filol. nauk. Volgograd, 2001.

10. Krjukov D.V. Sociolingvisticheskie harakteristiki pisem anglijskoj aristokratii Viktorianskoj jepohi [Sociolinguistic characteristics of the letters written by English aristocracy from Victorian era]: diss... na soisk. uch. stepeni kand. filol. nauk. Volgograd, 2001.

11. Magidova I.M. Teorija i praktika pragmalingvisticheskogo registra anglijskoj rechi [Theory and practice of pragmalinguistic register in English speech]: diss. na soisk. uch. stepeni d-ra filol. nauk. Moskva, 1989.

12. Pishhal'nikova V.A. Problema smysla hudozhestvennogo teksta. Psiho-lingvisticheskij aspekt. [The problem of the meaning of a literary text. Psycho-linguistic aspect]. Novosibirsk, 1992.

13. Sternin I.A. Obshhenie so starshim pokoleniem. [Communication with older generation] Izd.4, ispr. Voronezh: «Istoki», 2013.

14. Tislenkova I.A. Istoricheskie realii - markery rechi pozhilogo cheloveka [Historical realities-markers of an elderly person's speech]. Aktual'nye 
voprosy nauki: Materialy XXXVI Mezhdunarodnoj nauchno-prakticheskoj konferencii (09.02.2018) [Actual problems of science: Materials of the XXXVI International scientific and practical conference (09.02.2018)]. M.: «Sputnik+, 2018, pp. 62-64.

15. Tislenkova I.A. Kul'turno-istoricheskie realii proshedshej jepohi v rechi personazhej sovremennoj britanskoj dramy [Cultural and historical realities of the past era in characters' speech from modern British drama]. Izvestija VGSPU, №2 (125), 2018, pp. 132-136.

16. Tom Stoppard. Izobretenie ljubvi [The Invention of Love]. Azbuka-klassika, 2009.

17. Chizhevskaja M.I. Jazyk, rech'i rechevaja harakteristika: (Vopr. izuch. rechi personazha) [Language, speech and speech characteristics] / M.I. Chizhevskaja; MGU im. M.V. Lomonosova. M.: Izd-vo MGU. 1986.

18. Shahovskij V.I. Lingvisticheskaja teorija jemocij. [Linguistic theory of emotions ]. Monografija. M.: Gnozis, 2008.

19. Berstein B. Language and social context. London: Penguin Books, 1972.

20. Crystal D. The Cambridge Encyclopedia of the English Language. Cambridge, 2001.

21. Stoppard T. The Invention of Love. Grove Press. New York, 1997.

\section{ДАННЫЕ ОБ АВТОРАХ}

Тисленкова Ирина Александровна, к.ф.н., старший преподаватель кафедры «Иностранные языки», факультета экономики и управления

Волгоградский государственный технический университет ул. проспект имени В.И. Ленина, 28, г. Волгоград, 400005, Российская Федерация tislenkova@bk.ru

Глебова Екатерина Александровна, к.П.н., доцент кафедры «Иностранные языки», факультета экономики и управления Волгоградский государственный технический университет ул. проспект имени В.И. Ленина, 28, г. Волгоград, 400005, Российская Федераџия eaglebova@mail.ru 
Бганцева Ирина Владимировна, д.П.н., профессор кафедры «Иностранные языки», факультета экономики и управления Волгоградский государственный технический университет ул. проспект имени В.И. Ленина, 28, г. Волгоград, 400005, Российская Федерация irina07085@rambler.ru

\section{DATA ABOUT THE ATHOURS}

Tislenkova Irina Aleksandrovna, Senior teacher of the Foreign language Chair, Ph.D. in Philological Science, Faculty of Economics and Management

Volgograd State Technical University

28, prospekt imeni V.I. Lenina, Volgograd, 400005, Russian Federation

tislenkova@bk.ru

ORCID: 0000-0002-7202-2773

Glebova Ekaterina Aleksandrovna, Associate Professor of the Foreign language Chair, Ph.D. in Pedagogical Science, Faculty of Economics and Management

Volgograd State Technical University

28, prospekt imeni V.I. Lenina, Volgograd, 400005, Russian Federation eaglebova@mail.ru

ORCID: 0000-0002-2284-631X

Bgantseva Irina Vladimirovna, Professor of the Foreign language Chair, Ph.D. in Pedagogical Science, Faculty of Economics and Management

Volgograd State Technical University

28, prospekt imeni V.I. Lenina, Volgograd, 400005, Russian Federation irina07085@rambler.ru

ORCID: 0000-0001-5128-8858 